\begin{tabular}{|c|c|c|}
\hline PKS & Revista de GEOGRAFla & OJS \\
\hline $\begin{array}{l}\text { PUBLIC } \\
\text { KNOWLEDGE } \\
\text { PROJECT }\end{array}$ & $\begin{array}{c}\text { (RECIFE) } \\
\text { http://www.revista.ufpe.br/revistageografia }\end{array}$ & $\begin{array}{l}\text { OPEN } \\
\text { JOURNAL } \\
\text { SYSTEMS }\end{array}$ \\
\hline
\end{tabular}

\title{
AGROHIDRONEGÓCIO E DISPUTAS TERRITORIAIS EM ALAGOAS: NA BUSCA DE UMA APROXIMAÇÃO TEÓRICO- CONCEITUAL
}

\author{
Francisca Maria Teixeira Vasconcelos ${ }^{1}$ \\ ${ }^{1}$ Doutoranda em Geografia na Universidade Federal de Pernambuco. Email: franciscateixe@ gmail.com
}

Artigo recebido em 27/04/2017 e aceito em 06/06/2017

\begin{abstract}
RESUMO
No âmbito da discussão sobre a ampliação e reprodução do capital agroindustrial, por meio de grandes obras hídricas, destacamos o Canal do Sertão em Alagoas como recorte empírico no âmbito do agrohidronegócio. Isso posto, o presente artigo objetiva analisar, a partir do Canal do Sertão, as disputas territoriais no semiárido alagoano, uma vez que, mesmo antes da conclusão dessa grande obra hídrica, o agrohidronegócio tem se territorializado, intensificando a luta por terra e água em Alagoas. As águas da transposição no semiárido alagoano vêm intensificando a concentração da água e da terra entre latifundiários e grupos voltados para a produção de commodities agrícolas.
\end{abstract}

Palavras-chaves: Agrohidronegócio. Território. Conflito.

\section{AGROHYDROBUSINESS AND TERRITORIAL DISPUTES IN ALAGOAS: REFERENCES ON THEORETICAL AND CONCEPTUAL ASPECTS}

\begin{abstract}
Giving the discussion about increase and agroindustrial capital reproduction through great water works, we highlight the Wilderness Channel in Alagoas state as an empiral cut in the scope of agrohydropusiness. Thus, the goal of this study is to investigate through Wilderness Channel the development of agrohydropusiness and the territorial disputes in Alagoas. The idea is to understand the underlying causes of Wilderness Channel establishment, since before the conclusion of this great water works, the agrohydropusiness have been territorialized, causing many conflicts and process for land and water. The water deviated in Alagoas state do not represent the fact of qualitative changes in social structure, but on the contrary it has been intensifying the water and land concentration between landowners and groups Aimed at the production of agricultural commodities.

Keywords: Agrohydrobusiness, territory, conflict
\end{abstract}




\section{INTRODUÇÃO}

O início do século XXI é marcado pela implantação de uma cadeia de grandes projetos na América Latina. Esses projetos, ligados aos interesses do Estado e do mercado, estão voltados para os conglomerados agro-químico-alimentar-financeiros. A partir de vários tipos de incentivos e subsídios por parte do Estado e, aliados as disponibilidades de terra, água e mão de obra, o Brasil tem implantado vários projetos de infraestrutura com recursos oriundos da Iniciativa para Integração Regional Sul-Americana (IIRSA) e do Programa de Aceleração do Crescimento (PAC). Neste sentido, toda a implantação desse cenário tem sido sustentada a partir do discurso de desenvolvimento e da modernização, com atividades fortemente dependentes de terra e de água.

Nessa perspectiva, o Canal do Sertão Alagoano concebido na década de 1990, com recursos oriundos do Governo Federal e do Governo Estadual, sob o discurso de proporcionar mudanças amplas e profundas no que se refere ao desenvolvimento do semiárido alagoano, está destinado a múltiplos usos, dentre eles o abastecimento urbano e rural para o consumo humano e animal, irrigação, agroindústrias, piscicultura, turismo e lazer, abrangendo 42 municípios do agreste e sertão alagoano. Juntos correspondem a uma área de $10.431 \mathrm{~km}^{2}$, representando $71,3 \%$ de todo o vale do São Francisco alagoano e, em torno de 37,8\% do território do estado de Alagoas (MINISTÉRIO DA INTEGRAÇÃO NACIONAL, 2007). O canal, cujo traçado pode ser verificado na figura 1 , quando concluído, terá $250 \mathrm{~km}$ de extensão, dos quais, atualmente, foram concluídos e inaugurados $65 \mathrm{~km}$. Uma análise geral do projeto evidencia uma estrutura que fortalece o domínio das terras e da água para a difusão do agrohidronegócio, gerando novas formas de apropriação do território no semiárido alagoano. 


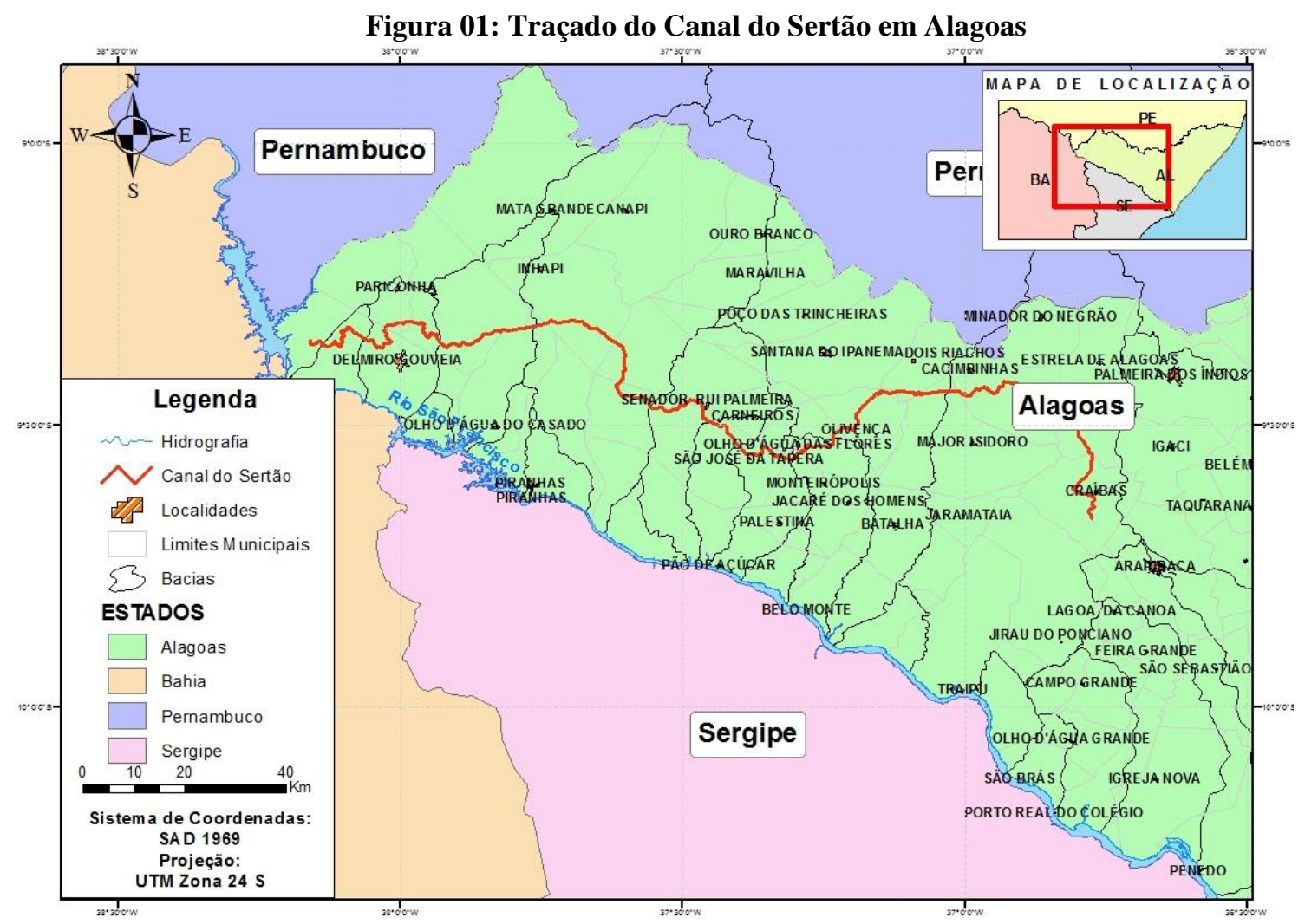

Fonte: Secretaria de Meio Ambiente e Recursos Hídricos - SEMARH (2014)

Isso posto, o presente artigo tem o objetivo de analisar, a partir do Canal do Sertão, as disputas territoriais no semiárido alagoano, uma vez que, mesmo antes da conclusão dessa grande obra hídrica, o agrohidronegócio tem se territorializado, intensificando a luta por terra e água em Alagoas.

\section{O TERRITÓRIO E A CONFLITUALIDADE COMO CATEGORIAS GEOGRÁFICAS PARA ANÁLISE DA PESQUISA: APONTAMENTOS TEÓRICOS INICIAIS}

A justificativa de compreensão da atual configuração socioterritorial da região Nordeste perpassa pela formação de novos territórios da água, através da estreita vinculação entre as formas de controle do território e da água, de maneira articulada. (TORRES, 2007).

Para Porto-Gonçalves (2006, p. 419) “[...] a água tem que ser pensada enquanto território, [...], com todas as suas contradições implicadas no processo de apropriação da natureza pelos homens e mulheres por meio das relações sociais e de poder”. O autor destaca ainda, o aspecto perverso contido no discurso sobre a escassez da água que tem sido cada vez mais reinventado, permitindo ao Estado criar, cada vez mais, mecanismos para implantação de uma agricultura capitalista. 
Nesse processo, uma nova lógica passa a redefinir o território a partir de diferentes relações sociais de produção, valores e hábitos. Uma nova dinâmica territorial se instala com todo o apoio da mídia, do Estado e de grupos empresariais nacionais e internacionais, afastando os sujeitos sociais que historicamente sempre estiveram presentes nessas áreas.

De acordo com Fernandes (2009, p. 440), “a conflitualidade é compreendida como processo inerente a desigualdade do desenvolvimento, ou seja, o desenvolvimento capitalista gera a conflitualidade que o promove". As várias faces do atual projeto desenvolvimentista do Estado revelam a perversidade do capital na expropriação do direito a água e a terra pelas comunidades que residem no semiárido, estimulando e reproduzindo as desigualdades sociais e gerando conflitos.

Entendemos que as diferentes formas de apropriação do território resultam em conflitos sociais centrados na questão do acesso à terra e água. Para Thomaz Junior (2010), as disputas e os conflitos em torno das porções do território que se inscrevem no agrohidronegócio oferecem-nos inúmeras oportunidades para a continuidade das pesquisas e leituras sobre a temática em questão.

\begin{abstract}
A evidente vinculação entre a expansão das áreas de plantio das commodities com a disponibilização dos recursos terra e água tem sido imprescindível para as estratégias do capital. Assim, a posse da terra e da água nos remete a refletir o papel do Estado no empoderamento do capital e seus efeitos no quadro social da exclusão, da fome, e da emergência da reforma agrária e da soberania alimentar. É dessa complexa e articulada malha de relações que estamos focando esse processo no âmbito do agrohidronegócio, por onde nos propomos entender os desafios para a sociedade, para os moradores da cidade e dos campos, ou seja, a dinâmica geográfica da reprodução do capital no século XXI e os cenários que põem para os trabalhadores. (THOMAZ JÚNIOR, 2010, p. 98-99).
\end{abstract}

Logo, o discurso que sustenta a prática intervencionista do Estado nas últimas décadas vincula-se dentro do chamado Paradigma do Capitalismo Agrário (PCA) (ABRAMOVAY, 1998). Para o PCA, a conflitualidade é analisada como processo à parte do desenvolvimento e é, inclusive, compreendida como obstáculo (Fernandes, 2009), pois acaba por lançar a ideia força de que a única perspectiva para o futuro esteja na transformação do camponês em agricultor familiar, cuja produção deva estar voltada para o mercado. Esta, segundo o paradigma citado, evidencia-se pelo emprego do trabalho assalariado, fundamentada na exploração econômica, com forte viés quantitativo na exploração da terra, aguçando a divisão de classes a partir da disputa entre a terra de negócio versus a terra de trabalho.

Temos buscado, a partir da conflitualidade, entendermos a teia de relações que envolve o Canal do Sertão em Alagoas. Essa obra hídrica proporciona a prática de relações externas e estranhas ao território através das ações de importantes grupos econômicos, que 
almejam, a partir da oferta da água, investir na produção em larga escala para acumulação de capital. Segundo Fernandes (2009, p. 200),

As disputas territoriais são, portanto, significação das relações sociais e de controle dos diferentes tipos de territórios pelas classes sociais. O território, compreendido apenas como espaço de governança, é utilizado como forma de ocultar os diversos territórios a garantir a manutenção da subalternidade entre relações e territórios dominantes e dominados.

Para o autor, as contradições, próprias do modo de produção capitalista e de suas relações sociais, geram conflitos territoriais. Segundo Montenegro (2010) as políticas direcionadas para a América Latina se inserem nesse contexto, uma vez que são perpassadas por,

Conflitos pela concentração fundiária, conflitos pela demarcação de terras indígenas, conflitos pela preservação ambiental, conflitos pela extração devastadora de recursos naturais, conflitos pela construção de megainfraestrutras, conflitos pela expansão do agrohidronegócio, conflitos pela produção de alimentos, conflitos pela manutenção de formas de vida tradicionais, conflitos pela expropriação, expulsão e exclusão dos camponeses e dos povos e comunidades tradicionais, conflitos pela implementação de estratégias de desenvolvimento (MONTENEGRO, 2010, p. 13).

Este movimento dialético que se imprime, inclusive no semiárido alagoano, nos faz refletir sobre o "afã desenvolvimentista" que norteou as políticas de desenvolvimento regional no Nordeste brasileiro, acirrando as desigualdades e a competitividade intra-regionais, bem como reafirmando o papel do Estado como mantenedor da hegemonia burguesa e industrial na região, ao longo dos últimos anos (MOREIRA DA SILVA, 2013).

O conceito de território neste trabalho tem como referência Fernandes (2009, 2010), para quem o território é formado por relações sociais que são perpassadas por relações de poder. O território é histórico e dialético, ou seja, se forma a partir do conflito e da contradição. Para Oliveira (2007) a configuração histórica do território acontece por meio da luta travada entre as classes sociais, gerando as disputas territoriais. As diversas políticas pensadas para o espaço agrário brasileiro têm gerado territórios e territorialidades distintas,

O território e a territorialidade,

[...] consistem em expressão geográfica que não são simples ocorrências, posição ou distribuição de objetos no espaço. Não é simples paisagem. Trata-se da ocorrência pertinente a ação. Ação que permite fixação, separação, uso, posse. Elas são o elo entre o ator e o objeto, resultam nas marcas objetivadas pela busca do domínio sobre o espaço. (HEIDRICH, 2009, p. 274-275).

De acordo com Saquet (2007, p. 113) "O território é condição de processos de desenvolvimento. É natureza e sociedade, manifestando-se de forma específica em diferentes lugares". As transformações territoriais no semiárido alagoano nos levam a busca de 
entendimento sobre a lógica capitalista que ali vem sendo implantada. O processo de reestruturação produtiva do capital que vem dando destaque aos projetos de desenvolvimento, tem se refletido em políticas públicas (cada vez mais excludentes) voltadas para o espaço agrário. Estas políticas públicas elegem territórios específicos para contemplar a lógica de um planejamento estratégico na tentativa de requalificar novos espaços e inserir o campo no contexto da modernização da agricultura. Nesse sentido, o capital busca espraiar-se tanto territorialmente, quanto em novos segmentos de atuação. Assim, em termos de uso do território, os países ou economias periféricas passam a ser alvo principal dessa nova etapa ou ciclo de acumulação (HARVEY, 2005).

O desafio teórico em debate, elucida processos sociais e conflitos em torno do acesso à terra e a água que engendram a prática das políticas públicas voltadas para o agrohidronegócio, sob a ótica do território, no semiárido alagoano onde tem surgido territorialidades, pautadas na disputa por terra e água entre o Estado, empresas transnacionais e os camponeses.

Assim, poder-se-ia afirmar que o Estado brasileiro teria atuado, ao longo da história das políticas de desenvolvimento rural, a partir de diferentes modos, voltado para as práticas de fomento da modernização da agricultura. Ou ainda, no desenvolvimento do campo através da execução da Reforma Agrária em diferentes acepções, do acesso a crédito e a extensão rural indistintamente (MOREIRA DA SILVA, 2013).

\section{NO CAMINHO DO AGROHIDRONEGÓCIO: CONFLITO POR TERRA E ÁGUA NO SEMIÁRIDO ALAGOANO}

Na américa Latina e, de maneira mais específica, no Brasil, a água tem sido um elemento central para o processo de reprodução ampliada do capital. Desde a segunda metade do século XX, o Nordeste tem sido espaço de implantação de um modelo agrário-agrícola, onde a água se apresenta como elemento essencial para a implantação de um modelo de desenvolvimento do campo a partir da criação de perímetros irrigados, transposição de bacias, construção de barragens etc. Esse movimento se insere dentro do processo de redescoberta do semiárido pelo capital agroindustrial, apresentando várias estratégias de reprodução. A materialização e ampliação de infraestrutura hídrica na região Nordeste tem transformado o espaço agrário, a exemplo do Projeto de Integração do rio São Francisco com as Bacias Hidrográficas do Nordeste Setentrional. 
Em Alagoas, a implantação do canal do sertão, aliada a outras obras, como a de perímetros irrigados em Delmiro Gouveia, Inhapi e São José da Tapera (alguns em fase de implantação e outros de estudo) tem proporcionado a valorização das terras localizadas na proximidade da obra, bem como a desterritorialização das famílias camponesas, posto que parte dessas terras estão sendo adquiridas por grupos empresarias de outras regiões ou de fora do país. Neste sentido, o antagonismo entre classes, típico dos espaços em que o agrohidronegócio se instala, tem se acirrado no alto sertão alagoano.

A problemática relativa ao agrohidronegócio tem apresentado consideráveis particularidades em Alagoas, redefinindo relações no âmbito da (re)produção do território. Ao longo da história do semiárido nordestino as obras hídricas têm gerado conflitos, uma vez que grupos oligárquicos, detentores do poder político e econômico ao captarem e se utilizarem de financiamentos do Estado, o utilizam em benefício próprio. Podemos nos utilizar do pensamento de Martins (1994, p.30), quando afirma que “(...) as transformações sociais e políticas são lentas, não se baseiam em acentuadas e súbitas rupturas sociais, culturais, econômicas e institucionais". Assim, as águas da transposição em Alagoas vem intensificando a concentração da água e da terra entre as poucas famílias latifundiárias do estado e grupos empresariais.

Portanto, é nesse cenário de conflitos que, no sertão alagoano, pode constatar-se, a partir da conclusão e inauguração do trecho 3, que a água do Canal do Sertão, tem como objetivo central abastecer e garantir a segurança hídrica dos latifúndios por onde a obra irá passar e de empresas agrícolas que começam a chegar na região. No cerne dessa discussão, o Governo do Estado tem oferecido uma serie de subsídios para os supracitados grupos e tem divulgado, nas suas páginas oficiais, uma cartilha no sentido de atrair "empreendimentos" voltados ao desenvolvimento da fruticultura irrigada, na região do sertão e semiárido, inclusive com incentivos fiscais, creditícios e locacionais do Governo estadual, alegando a disponibilidade de mão de obra, terras férteis, água e condições climáticas favoráveis a fruticultura irrigada. Em Delmiro Gouveia, a primeira outorga para uso da água, foi autorizada para o maior latifundiário e importante político do município. Enquanto isso, para os pequenos produtores rurais do sertão alagoano, nenhuma ação, até o momento, foi efetivamente executada.

Podemos afirmar que o Estado brasileiro tem viabilizado, a partir da transposição, as necessárias estratégias para reprodução do capital. A nível de Alagoas e em pleno século XXI, esse histórico de benefícios direcionados, por parte do Estado, para as elites locais, tem se 
reproduzido a partir de uma política pública que nasceu, sob o discurso e a justificativa de gerar desenvolvimento e de permitir o acesso a água a milhares de camponeses do sertão e agreste alagoano. O Canal do Sertão, nos permite afirmar, a partir já dos seus primeiros trechos, que as famílias camponesas do sertão alagoano, continuam sem acesso a água e sem expectativas de irrigar a terra para a produção agrícola. Uma análise prévia do traçado do canal, permite-nos afirmar que este, a todo custo e sem maiores justificativas, serpenteia os latifúndios da região, ao invés das pequenas e médias propriedades. Os projetos de transposição no semiárido nordestino e alagoano dão continuidade ao modelo excludente e concentrador de terra e água, sendo o Estado legitimador e mantenedor dos interesses particulares, luxos e vaidades das oligarquias agrárias (CUNHA, 2014).

As disputas em torno do acesso e uso das águas da transposição em Alagoas, já compõem a realidade local. Membros da sociedade civil têm se organizado e se mobilizado em função da garantia da água para os que dela, de fato necessitam. A seguir, destacamos diversas ações de movimentos sociais na luta contra o capital em Alagoas:

a) O Seminário Canal do Sertão: Para quê? Para quem? Organizado pela Comissão Pastoral da Terra (CPT) e pelo Grupo de Estudos Agrários e Socio-Territoriais (GEAST). O mesmo foi realizado na UFAL/Campus do Sertão no dia 28 de agosto de 2015, onde estiveram presentes 650 participantes, entre camponeses e camponesas, quilombolas, indígenas, poder público e estudantes;

b) A Romaria das Águas e da Terra realizada no dia 26 de setembro, onde participaram em marcha até a obra do canal, cerca de 2.000 pessoas;

c) A formação do Fórum em Defesa das Águas do Canal do Sertão, constituído pelas seguintes representações: CPT, MST, Conselho Indigenista Missionário (CIMI), Sindicatos de Trabalhadores Rurais (STR), UFAL, dentre outros;

d) Ocupação de propriedades as margens do Canal por famílias de trabalhadores rurais sem terra, no sentido de garantir o acesso a água e a terra (Acampamentos Nelson Mandela e Maria Dolores);

e) Falta de condições financeiras dos camponeses para a irrigação e produção agrícola.

O embate contra as políticas desenvolvimentistas do Estado travado pelos camponeses e movimentos sociais tem se dado na busca de garantir o acesso à terra e a água. A luta tem sido pela conquista da terra de trabalho e contra toda a tentativa do Estado em manter e dar continuidade a terra de "negócio"concentrada nas mãos de poucas famílias e de grupos empresariais. As disputas territoriais em Alagoas, a partir da territorialização e monopolização 
do território pelo agrohidronegócio, tem nos exigido novas leituras e interpretações sobre o processo de resistência do campesinato em Alagoas.

\section{ALGUMAS CONSIDERAÇÕES}

A mercantilização da terra e da água tem intensificado o processo de territorialização do capital no espaço agrário brasileiro, assim como uma maior aplicação de tecnologia, exploração e expoliação da mão-de-obra, intensificando o cenário de conflitos entre o Estado, camponeses e movimentos sociais. Nossas análises inferem que as águas da transposição em Alagoas escorrem na direção do agrohidronegócio, redefinindo a geografia política, econômica, cultural e ambiental do semiárido alagoano, contribuindo, assim, para a expansão do capital no campo, cujo principal reflexo no território tem sido novas formas de desigualdade social.

Entende-se que essas ações do Estado necessitam de melhor compreensão por parte da academia, com o intuito de analisar como as ações públicas perfazem o território, a partir das implicações do agrohidronegócio em uma região semiárida de Alagoas.

\section{REFERÊNCIAS}

ABRAMOVAY, R. Paradigmas do capitalismo agrário em questão. 2ed., São Paulo/Campinas: Mussite/Editora da Unicamp, 1998.

CUNHA, T. B. O Agrohidronegócio no Contexto da Transposição do rio São Francisco no Semiárido Nordestino Brasileiro. Anais do VII Congresso Brasileiro de Geógrafos, Vitória/ES, 2014.

Documentos do colegiado do Território do Alto Sertão Alagoano: PDTRS do Alto Sertão Alagoano. MDA/SDT/PRONAT/CIAT, 2007.

FELÍCIO, M. J. A conflitualidade dos paradigmas da questão agrária e do capitalismo agrário a partir dos conceitos de agricultor familiar e de camponês. In: CAMPO-TERRITÓRIO: revista de geografia agrária, v.1, no 2, pp. 14-30, ago, 2006.

FERNANDES, B. M.; MEDEIROS, L. S.; PAULILO, M. I. (orgs). Lutas camponesas contemporâneas: contradições, dilemas e conquistas. São Paulo: Editora UNESP; Brasília, DF: Núcleo de Estudos Agrários e Desenvolvimento Rural, 2009.

. Sobre a tipologia dos territórios. In: SAQUET, M. A., SPÓSITO, E. S. (orgs). Territórios e Territorialidades: teorias, processos e conflitos. São Paulo: Expressão Popular, 2009, p. 197-215.

. Formação e Territorialização do MST no Brasil. In: CARTER, Miguel. (org.). Combatendo a desigualdade social: o MST e a reforma agrária no Brasil. São Paulo: UNESP, 2010.

HARVEY, David. A produção Capitalista do Espaço. São Paulo Annablume, 2005. 
HEIDRICH, A.L. Espaço e multiterritorialidade entre territórios: reflexões sobre a abordagem territorial. In: IV Seminário Estadual de Estudos Territoriais; II Seminário Nacional de Múltiplas Territorialidades. Francisco Beltrão: UNIOSTE, 2009

MARTINS, José de Souza. O poder do atraso: ensaios de sociologia da história lenta. São Paulo: Hucitec, 1994.

MONTENEGRO, J. Conflitos pela terra e pelo território: ampliando o debate sobre a questão agrária na América Latina. In: Geografia agrária, território e desenvolvimento. São Paulo: Expressão Popular, 2010, p. 13-34.

MOREIRA DA SILVA, C. N. O território nas políticas de desenvolvimento rural do ministério do desenvolvimento agrário (MDA): consenso ou conflito? Tese (doutorado) Universidade Federal do Ceará. Fortaleza: UFC, 2013.

OLIVEIRA, A. U. de. A longa marcha do campesinato brasileiro: movimentos sociais, conflitos e reforma agrária. In: Caderno de Estudos Avançados, v. 15, no 43, São Paulo, Set/Dez, 2001.

- Geografia agrária: perspectivas no início do século XXI. In: OLIVEIRA,Ariovaldo U. Modo capitalista de produção, agricultura e reforma agrária. São Paulo: FFLCH/Labur Edições, 2007.

PORTO-GONÇALVES, Carlos Walter. A globalização da natureza e a natureza da globalização. Rio de Janeiro: Civilização Brasileira, 2006.

RAMOS FILHO, E. da S. A ofensiva do capital no campo brasileiro e a resistência do campesinato. In: REVISTA NERA, ano 8, nº 6, pp. 46-58, Presidente Prudente: Jan/Jun, 2005. SAQUET, M. A. Abordagens e concepções sobre o território. São Paulo: Expressão Popular, 2007.

SEINFRA - Secretaria de Estado de Infra-Estrutura. Ministério da Integração Nacional (2007). "Ficha Técnica. Acompanhamento de Obras: Canal Adutor do Sertão Alagoano",Brasília, 2007. 26 p.

THOMAZ JÚNIOR, A. O Trabalho como Elemento Fundante para a Compreensão do Campo no Brasil. In: XVI Encontro Nacional de Geografia Agrária. pág. 128-139. 2003.

. Jogo de cena e poder de classe no Brasil do século XXI: a contra-reforma agrária no governo Lula. Revista Perspectiva Geográfica, EDUNIOESTE - Cascavel, v. 1, n.1, p. 9-24, 2005.

- A geografia do mundo do trabalho na viragem do século XXI. Revista Geosul, v. 19, n. 37, p. 7-26, jan./jun. 2004.

. Trabalho e Territórios em disputa: Algumas considerações. In: PAULINO, E. T., FABRINI, J. E. Campesinato e territórios em disputa. São Paulo: Expressão Popular, 2008.

. O agrohidronegócio no centro das disputas territoriais e de classe no Brasil do século XXI. Campo-Território: revista de Geografia Agrária, v. 5, n. 10, p. 92-122, agosto de 2010. TORRES, A. T. G. Hidroterritórios (novos territórios da água): os instrumentos de gestão dos recursos hídricos e seus impactos nos arranjos territoriais. Dissertação (mestrado), UFPB, João Pessoa, 2007. 